\title{
'Some Refugees Move because the Health Facilities in the Settlement are not Good': A Qualitative Study of Factors Influencing Movement of Somali Refugees from Nakivale Settlement to Kampala City
}

Pape Bagonza ( $\sim$ papeglam@gmail.com )

UMU: Uganda Martyrs University https://orcid.org/0000-0002-4559-3167

TADDEO KYALIGONZA

Uganda Martyrs University

ARTHUR BAGONZA

Makerere University College of Health Sciences

\section{Research}

Keywords: Refugees, Movement, Settlement, Urban Centre, Kisenyi, Kampala, Uganda

Posted Date: August 30th, 2021

DOl: https://doi.org/10.21203/rs.3.rs-832372/v1

License: (c) (1) This work is licensed under a Creative Commons Attribution 4.0 International License.

Read Full License 


\section{Abstract}

Background: There is a growing number of urban refugees that may necessitate local government and humanitarian organizations to factor in when planning for the urban infrastructure as this has proved to be a planning blind spot. This study assessed factors influencing Somali refugee movement from Nakivale refugee settlement to Kampala, the capital city of Uganda.

Methods: Six key informant interviews were held with the Principle Protection Officer-OPM, Legal Coordinator-NRC, Manager Access to Justice Program-RLP, Psychosocial Counsellor-JRS, Somali elder Nakivale settlement and the Chairperson-SCK. Three focus group discussions were conducted with one group of male and two groups of female Somali refugees. Transcripts were managed using Atlas ti version 7 (ATLAS. Ti GmbH, Berlin).

Results: The need for better basic needs such as food, water, health care, education, employment, a better quality life and difficulties related to having a language barrier emerged in the first theme. Movement due to political and cultural persecution emerged as a combined theme of security. The need for better economic benefits, livelihood support and an enabling refugee policy were influencers. The study also revealed that Somali refugees are a well-knit society with a robust communication network that relies on Islamic religion and country background in exploiting connections that enable those who move from Nakivale settlement to quickly adapt to the situation in Kampala.

Conclusion: Somali movement from Nakivale refugee settlement to Kampala is influenced by a need for better basic needs and security; economic benefits, livelihood support and an enabling refugee policy which guarantees freedom of movement. A communication network based on religion and country background are facilitators.

\section{Introduction}

According to the United Nations High Commission for Refugees (UNHCR), by 2018, the top ten countries contributed 16.6 million or $82 \%$ of the refugee population in the world. Out of these, seven were from Africa (1).

In many African countries- Uganda inclusive, refugee movement is triggered by civil wars, ethnic strife, land disputes, exploitative relationships, to mention but a few $(2,3)$.

In many countries where refugees are hosted, there is a curb on freedom of movement especially where policies are designed to confine refugees to camps(4). Refugees in such camps have been noted to have many challenges like inadequate housing, lack of infrastructure, general poverty, high unemployment, low educational attainment and poor physical and mental health (5). Vivid examples have been documented among Burmese refugees in Thailand and Syrian refugees living in Domeez camp in Iraq $(5,6)$. It is because of such poor living conditions that refugees and asylum seekers are forced to make a conscious decision to leave and move to urban centres. 
Understanding what triggers this urge to move and putting in context this abstract behaviour of movement can best be done using proven theories such as the Doyal and Gough's theory of human needs (7). This theory predisposes that basic, primary and intermediate human needs when adequately satisfied enable individuals to achieve a given end which in most cases is the well-being of the human. If a given end is not met, humans are very likely to experience harm such as ill-health, malnutrition and bodily injuries $(8,9)$.

In Uganda, the UNHCR which is the lead agency for refugees endeavours to make sure that lives are saved and rights are protected. UNHCR partners with governments and non-profit organizations to support refugees, asylum seekers and the communities hosting them. UNHCR ensures that people have the right to seek for asylum and find refuge from violence and persecution. It also has the mandate to find durable solutions for refugees. UNHCR complements the work of states in protecting refugees and ensuring that they are treated according to legally recognized standards.

Refugees in settlements get the bare minimum requirements such as shelter, water, food and healthcare that guarantee survival. All refugee settlements have relatively well equipped health centres and medical personnel besides the schools that provide basic education for children. On the other hand, the government of Uganda gives each refugee household a plot of land for agriculture and much needed refugee documentation. The government of Uganda through the Office of the Prime Minister (OPM) is responsible for receiving and documenting refugees and asylum seekers, facilitating refugee status determination and coordinating actors who provide services for refugees and the host communities. The government of Uganda aims at ensuring that refugees in Uganda enjoy the same rights as nationals which include but are not limited to enjoyment of effective, efficient, timely delivery of services, safety and security.

Despite these provisions, Somali refugees continue to move from Nakivale refugee settlement to urban centres, the main one being Kisenyi in Kampala- the capital city of Uganda. According to a UNHCR refugee statistics report, there are 26,960 Somali urban refugees in Kampala- majority of whom prefer to settle in Kisenyi(10). The same report indicates that these refugees leave settlements due to limitations they face as a result of being confined to settlement life.

The Doyal and Gough's theory of human needs(7) aids in identifying universal satisfier characteristics for things that are essential for basic needs and can also be used as a lens for examining how Somali refugees practice their autonomy after leaving the settlement and moving to urban centres such as Kisenyi.

Worth noting is that the aforementioned movements of the Somali refugees are enshrined in the guiding legal framework for refugees article 26 of the 1951 convention which stipulates that refugees should be allowed freedom of movement(11). Being a signatory to many UN charters and conventions, Uganda's refugee policy is also aligned in such a way that under Sect. 30 of the Refugees Act 2006, refugees in Uganda are allowed freedom of movement and the right to self-settle if the refugee so chooses. However, 
factors behind the movement of Somali refugees from Nakivake refugee settlement to Kisenyi in Kampala are not yet clearly understood.

Aim of the study

Overall, this study aimed at assessing factors influencing movement of Somali refugees from Nakivale settlement to Kisenyi- an urban center in Kampala, the capital city of Uganda.

To achieve this objective, the study assessed the living conditions of Somali refugees in Nakivale settlement, explored the opportunities that Somali refugees exploit once they reach Kisenyi and investigated the role of Somali ethnic support networks in assisting refugees when they get to Kisenyi, Kampala.

\section{Methods}

The consolidated criteria for reporting qualitative research (COREQ) guidelines were used to guide the methods and ultimate reporting of this study (12)

Design of the study

A descriptive qualitative study design employing both focus group discussions (FGDs) and key informant interviews (KIls) was used to understand factors influencing movement of Somali refugees from Nakivale settlement to the urban centre of Kisenyi in Kampala. Choice of using a qualitative descriptive study was based on the fact that the researchers wanted to stay as close to the data and information collected as possible in line with recommendations by Sandelwoski $(13,14)$.

\section{Participant selection}

This study purposively selected Somali refugees in the urban centre of Kisenyi and key informants from leading refugee organisations in Kampala because they were knowledgeable and were able to give rich and detailed information about the phenomenon of interest, a major attribute of qualitative studies(15). Moreover, the purposively selected Somali refugees and key informants comprised a sample that was logically assumed to be representative of the population of Somali refugees moving from Nakivale settlement to urban centres(16).

Initially, phone calls were made to the chairman of the Somali refugees in Kisenyi informing him about the aim and objectives of our study. This was followed by a face to face visit where we asked him to gather for us Somali men and women who had moved from Nakivale settlement to Kisenyi in Kampala, Uganda's capital city. Having been found to be knowledgeable about movement of Somali refugees from Nakivale settlement to Kisenyi, we sook informed consent from the chairman of the Somali community and conducted a key informant interview with him. Besides agreeing to the key informant interview, the chairman gathered two different groups of women and one group of men for focus group discussions (FGDs). 
All participants invited for the study allowed to be interviewed. However, government restrictions which included lock downs made it difficult for us to conduct interviews with the desired number of focus groups.

Setting of the study

The study was carried out in Kisenyi which is found in Kampala- the capital city of Uganda. While Kisenyi is home to refugees from nations such as the Democratic Republic of Congo (DRC), Rwanda, Burundi as well as a few Ugandan nationals, majority of refugees in the area are of Somali origin. A face to face key informant interview was conducted with the chairman of the Somali community and focus group discussions were held with the three different groups of Somali refugees in a quiet and spacious restaurant. Before the interviews began, all severe acute respiratory syndrome coronavirus 2 (SARS- $\mathrm{C}_{0} \mathrm{~V}$ 2) standard operating procedures such as observing social distance, washing hands and wearing a face mask were enforced. The interpreters helped to explain the purpose of the study and informed consent was sought prior to commencement of the interviews. Besides the moderator, note taker and study participants, the waiter of the restaurant was the only person allowed in the room during interviews because he had to serve study participants with refreshments.

People who were not part of the study were asked to remain outside the restaurant for the duration of the focus group discussions in order not to create any bias. Only one focus group discussion was held per day and lasted a maximum of one and a half hours. On the other hand, key informant interviews were conducted from the offices of the people being interviewed. The interviews were conducted on appointment when the person being interviewed was not busy.

Three focus group discussions (FGDs) were conducted with refugees who had moved from Nakivale refugee settlement in September 2020. One focus group discussion (FGD) was held with males while two FGDs were held with females. The male group had seven participants while one of the female groups had eight participants and another seven.

In all FGDs, more males $5(71.4 \%)$ had a higher level of education compared to females while more females 11 (73.3\%) were married compared to men (results not displayed).

Key informants enrolled in the study were purposively chosen from the Office of the Prime Minister (OPM), the Refugee Law Project (RLP), Norwegian Refugee Council (NRC) and Jesuit Refugee Service (JRS) since these are the lead agencies dealing with movement of refugees in Uganda. In addition an elder from the Somali community in Nakivale settlement and the chairman of the Somali community based in Kisenyi, Kampala were interviewed as key informants. The key informant interviews were conducted in August 2020 and while we asked participants in the FGDs how long they had spent in Kampala, this was not done for the key informants since all of them had been in Kampala for more than ten years. Table 1 illustrates more socio-demographic characteristics of the interviewed participants. 
Table 1

Socio-demographic characteristics of participants

\begin{tabular}{|lll|}
\hline Variable & Participants & \\
\hline Gender & Key informants (N) & FGDs (N) \\
\hline Male & & 7 \\
\hline Female & 4 & 15 \\
\hline Average age in years (SD) & 2 & \\
\hline Male & & $35(11)$ \\
\hline Female & $49(17)$ & $39(10)$ \\
\hline Average time in months spent in kampala (SD) & $32(9)$ & $35(42)$ \\
\hline Male & - & $43(32)$ \\
\hline Female & - & \\
\hline
\end{tabular}

Data collection

An interview guide was developed by the investigators of the study based on themes of migration from published evidence and reports. The focus group discussion guide was pre-tested in a community with Ethiopian refugees since Somalis and Ethiopians are close neighbours and have similar social cultural characteristics (17). The key informant interview guide was pre-tested on five respondents who are staff of the Uganda Red Cross (URC), Alight, United Nations High Commissioner for Refugees (UNHCR), Care and Assistance for Forced Migrants (CAFOMI) and the Danish Refugee Council (DRC).

The aim of the pre-test was to make sure that questions in the interview guide accurately captured all the views from study participants as intended by the study(18). Where the investigators of the study felt that insufficient information was given by respondents during the pre-test, probes and where necessary prompts were inserted in the part particular question of the interview guide.

Due to the ever increasing number of patients with SARS-COV-2 in the community coupled with an unexpected lock down, it was hard for the study team to carry out repeat interviews.

Interviews from the FGDs and Kls were audio recorded and transcribed verbatim using Atlas ti.7 software. The focus group discussions took 90 minutes while the key informant interviews lasted 60 minutes on average. Field notes were made during the interviews with participants.

While we set out to conduct at least six focus group discussions with each of the gender as a bare minimum, this was not possible as the study was cut short by government SARS-COV-2 restrictions on movement. None the less, the prompts and probes inserted in the focus group discussion guide ensured 
that all the relevant information was obtained from the study participants in the three focus groups that were interviewed. Collection of information from the study participants went on until there were no new emerging issues- a phenomenon commonly referred to as saturation (19).

As far as the key informants were concerned, saturation occurred after the fourth interview. Never the less, two more interviews were conducted to make sure that indeed, there were no new emerging issues.

Transcripts from the audio recordings of the focus group discussions were returned to three members of the male focus group for comment and or correction since they were more educated than the females. Also, three transcripts were returned to key informants from RLP, OPM and the chairman of the Somali community in Kisenyi for comments and or corrections.

\section{Data analysis}

Transcription of the nine interviews was carefully done over a fourteen day period. The transcripts were then uploaded into Atlas ti version 7software (ATLAS.ti GmbH, Berlin) where they were coded by PMB and $A B$. An interpretivist ontological and constructivist epidemiological position were assumed by PMB who was a masters student at the time data on movement of refugees from settlements to urban centres was collected and socially constructed (20-22). That is to say, besides refugee movements being regulated by policies governing settlements, the lived experiences of Somalis that were interviewed in Kisenyi, Kampala were socially constructed. Therefore, the data was analysed mainly with an intention of understanding factors underpinning the movement of Somali refugees from Nakivale refugee settlement to Kisenyi in Kampala, Uganda's capital city.

Text from uploaded transcripts was first divided into meaning units before they were processed into condensed meaning units (23). PMB abstracted and labelled the condensed meaning units generating over 35 codes from the first two KII and FGD transcripts. Comparison and consensus was done by PMB and $A B$ on the generated codes before they were merged.

The agreed-upon codes formed the basis for coding the subsequent transcripts which is believed to have increased the trustworthiness of the results $(24,25)$. In addition, it is believed that the interpretive rigour of the study was improved by having two people code the transcripts independently and agree on the codes before they were merged $(24,26)$.

After coding all the transcripts, the codes were analysed for similarities and merged further to form subthemes. The sub-themes were also compared and aggregated to form thicker, higher-order themes. The themes were analysed using template analysis- a method used by researchers who have codes at the start of the analysis but also allow the generation of new codes when information arises from subsequent interviews and needs new codes $(27,28)$. Given the restrictions on movement prevailing at the time the data was collected, participants involved in the study were not able to provide feedback on the findings. 


\section{Results}

We set out to assess factors influencing movement of Somali refugees from Nakivale settlement to Kisenyi- an urban center in Kampala, the capital city of Uganda. Results for achieving this objective are presented thematically under each of the following specific objectives:

\section{Assessing the living conditions of Somali refugees in Nakivale settlement}

Two broad themes namely basic needs and security emerged from the data collected under this specific objective. Our results show that the need to fulfil their basic needs and ensure personal security contributes to Somalis leaving Nakivale settlement and moving to Kisenyi, Kam

Food was the first basic need mentioned by majority of the key informants interviewed. They mentioned that the food provided in the settlement is different from what the Somalis are used to eating back home and this presented a challenge. They mentioned that Somalis exchange their food rations so they can buy what they can eat.

"... There is also a lot of scramble when food rations are being distributed. The Somalis usually have problems with the food supplied. In settlements they are given posho and beans yet they are used to eating rice and meat back home. The food supplied is not what they prefer to eat so they usually exchange with other refugees for money so they can actually buy what they prefer to eat."(KII, JRS)

The respondents in both the male and female FGD's mentioned that they were not familiar with the food provided by the World Food Programme (WFP) and as such, struggle to consume it. Both the female and male participants had issue with the type of food being supplied and the lack of additional ingredients like oil and salt to prepare the food. It is interesting to note that one of the male participants mentioned that there is no food in Nakivale. The female participants were more vocal and detailed about what food was provided in Nakivale and what their food preference was. The female participants said that they were used to eating meat, rice and spaghetti mainly.

"We are used to eating spaghetti, rice, meat and milk so we don $t$ know how to eat the food they give to us. When they provide us with this maize and beans it requires many other things to prepare them like fuel say charcoal oil but they don't even give us cooking oil the money we are given too is so little"(FGD 1, females)

The second basic need mentioned was water. Officials from the OPM charged with welfare of refugees in Nakivale refugee settlement stated that the water quality is good and that it goes through water purification processes before it is distributed to refugees. It was mentioned that Nakivale has a piped water system with constant supply though they were not sure if it was adequate. 
"The quality is good because it goes through the processes of purification before it is moves to the public it's like water you get from National water. Yes, the chemicals are added in the water as purification is done as they release it to move" (KII, OPM)

From the perspective of the refugees, water quality and supply was also another challenge that they faced in the settlement and was a reason for their moving to the urban centre. The water challenge was more prominently mentioned by members in the male FGD. Safe and clean water is a basic right but in Nakivale the water seems to be a challenge for the refugees. A female participant, 30 years, mentioned that she was allergic to the water in Nakivale. Three male participants aged 22, 25 and 45 also stressed about the challenge of inadequate supply and quality of water being a motivator to relocate to the urban in search of a better life.

"...the water supply is low and is not adequate. The queue is so long that it is easier to buy." (FDG, Male)

The third basic need mentioned was the need for better health care. An official from OPM mentioned that Nakivale settlement had reasonably good healthcare with five ambulances which took referral cases from the settlement to Mbarara regional referral hospital whenever there was need to. Another key informant mentioned that although Nakivale settlement had a health centre, it was not equipped enough to handle certain medical issues which needed specialized treatment.

"I should also mention that at least some refugees move because the health facilities in the settlement are not good. In Nakivale, there is a health centre but then you realise it's not equipped and doesn't have enough workers. So, if someone has a complication or a sickness that needs surgery, they can't do it that side. So, they rather move to Kampala where they get better facilities."(KII, RLP)

In the focus group discussions, the refugees interviewed mentioned inadequate healthcare in Nakivale refugee settlement as one of the reasons that contributed to their leaving. The issue of inadequate healthcare was raised more prominently with the female respondents more than the male respondents. Thus refugees perceived the healthcare in Nakivale to be lacking because the health centre is not equipped to handle certain health conditions for example situations where surgery might be required.

"I came here from Nakivale because I and my children were sick. We didn't get any healthcare from Nakivale that's why we came here, to seek medical care. And I am now diabetic. So, I can't go back there because there is no health care, I need to stay here and get medication."(FGD2, female)

Employment and a better standard of education was another reason why Somali refugees leave Nakivale settlement. Majority of the key informants agreed that the refugee settlement did not offer adequate jobs and that the standard of education in Nakivale is not good compared to the urban settings.

"Nakivale settlement has only one secondary school and not everyone would be accommodated there. Beyond secondary education, there is not much provision in the settlement so most of them come to Kampala to get that education" (KII, RLP). 
"There is not much work to do there as it is a village setting and Somalis are not used to living in a village. Also, the life is generally not good" (KII, Chairperson SCK).

The Somali refugees in the focus group discussions mentioned that they leave Nakivale refugee settlement to find a better standard of education because the one in Nakivale is poor and not to standard. The issue of moving to Kampala in search of better standard of education was mainly stressed by the male respondents more than the female ones.

"... I came to Kisenyi Kampala because first and foremost there is no education but in Kampala there is education. In addition, you get support from Refuge Law Project and the Somali community. There is no education, no clean water in Nakivale, poor health facility and poor services and even the schools are there but very poor. Communication to our families is cut off too while in Nakivale, no internet so we come here because we can communicate to our families better. The other issue is that people in Nakivale cannot support each other everyone is struggling on his own.... " (FGD, male).

Besides the aforementioned basic needs, security was another reason mentioned as to why Somali refugees leave Nakivale settlement for Kisenyi in Kampala. Majority of the key informants said that security in Nakivale refugee settlement was good while others intimated that a lot still had to be done. There are different types of insecurity that refugees face and may arise as a result of political persecution, cultural persecution, issues of discrimination and a need to secure themselves by keeping their registration in the settlement intact.

"..Yes, refugees flee for different reasons. Sometimes, it is because of political persecution if they are opposing the ruling government in Somalia. If they are human rights activists in Somalia and they come to Uganda, they may continue following them because they have information that may be detrimental to their government. So, they are safer moving to Kampala or being re-located to another country for their safety" (KII, RLP)

The refugees however were not keen to discuss political persecution openly and instead took a discreet route bordering lack of protection:

".. the organisations in charge of protection do not work at all. Whenever we try to voice our issues and complaints, we get no assistance from the authorities of Nakivale settlement. So, we decide to come here although we have no support as well" ( $F G D$, male).

Determining opportunities that Somali refugees exploit once they reach Kisenyi, Kampala.

Three broad themes namely; economic benefits, livelihood support and enabling policy emerged from the data collected for this specific objective. Our results show that Somali refugees exploit opportunities through economic benefits, livelihood support and through the availability of an enabling policy.

As far as economic benefits were concerned, most of the key informants intimated that by nature, Somalis are urban dwellers who tend to gravitate towards the city to exploit business opportunities that 
are available in Kisenyi. The Somali refugees therefore find that the incentive of a plot for agriculture in the settlement does not benefit them and would rather engage in business. As such, the Somali refugees who are not able to get opportunities in the settlement tend to relocate to the urban centre in Kisenyi where there is a wider pool of opportunities, a big customer base and market.

"If they get food to eat and where to sleep, what else? You know, because they are not going to get a hoe and dig like most of the rural populations of the African dissent, you find that as they settle down, they come to town where they can do some business since they are business oriented people. They also get some kind of social protection and support from their communities who are predominantly in Kisenyi" (KII, OPM)

The refugees held the same view as the key informants that were interviewed. The urban centre (Kisenyi) has better opportunities for them as far as business and job opportunities are concerned.

"... we talk to other Somalis who have shops and ask for jobs even if we don't know them. We just talk and see if they can solve our problems."(FGD1, female)

Livelihood support was another theme that emerged while determining opportunities that Somali refugees exploit when they reach Kisenyi in Kampala. Majority of the key informants mentioned that the Somali refugees benefit from the opportunity of livelihood support through exploiting opportunities that are provided by different organizations such as RLP, JRS, and NRC that support refugees in urban centres such as Kisenyi in Kampala. Some give livelihood skills while others offer medical support. The kind of support given depends on the mandate of the organization.

"Under Livelihoods we train refugees on basic skills like making necklaces for sell, art and craft, catering, baking, fashion and design. They learn tailoring, hair dressing, electronics repair and maintenance. We also give start up loans to those who have completed livelihood training and this loan is given interest free" (KII, JRS)

While a few Somali refugees reported to have benefited from opportunities offered by organizations that support urban refugees, majority of the participants in both the male and female FGD's independently verified that they had never heard of such organisations. For those that had heard about the organisations, they were denied service because they were registered in the settlement.

"We thought we were going to get support from organisations which support refugees but unfortunately we didn't get any. We had expectations of getting education financial support" (FGD, male)

Having an enabling refugee policy in place is the other opportunity Somali refugees exploit when they reach Kisenyi in Kampala. It should be noted that Uganda has a friendly refugee policy implemented through OPM which allows refugees freedom to exploit the available opportunities in the urban centre. This policy enables refugees to carry out their day-to-day activities without unnecessary interference. Furthermore, OPM plays a vital role of providing necessary refugee documentation that allows refugees to go about their business in the urban centre and also provides them with protection. 
"We have a comprehensive refugee response framework in place. It was adopted after the new declaration on refugees and migrants. Out of it, we are expanding our integrated planning for refugees in the host communities. When you look at the NDP III, even NDP II, refugee components were considered in national planning. I think under the NDP, it is more elaborate so you will find that in terms of planning, we are encouraging for example districts or city authorities to do comprehensive planning like taking care of even the urban refugees into their planning."(KII, OPM).

The refugees on their part mentioned that the government provided them with security and freedom of movement. These are two important aspects why Uganda is favoured as a refugee destination because there are many countries where refugees are restricted to particular areas and not allowed to move. Once a refugee is properly documented in Uganda their freedom of movement is unrestricted under the Refugees Act, 2006. Such enabling policies ensure that the refugees are able to enjoy their rights in Uganda. A participant from the FGD (female) mentioned that refugees in Uganda enjoy freedom of movement:

"I take Uganda as my second country; no other country is like Uganda. Kenya is our neighbour but they are the worst country in the world because they behave badly. The corruption is high in that they will arrest you and ask you for money. In Uganda, it is peaceful with no corruption and so Somalis move freely when they go to Kampala. That's why they even move away from here [Nakivale]" (FGD, Female).

Investigating the role of Somali ethnic support networks in assisting refugees when they get to KisenyiKampala

One broad theme namely; nature of the Somali community emerged under this third specific objective. Our results show that the nature of the Somali community is what helps Somali refugees assist each other in Kisenyi.

Majority of the key informants mentioned that the Somali community is quite different from other refugee communities. Their community is a closed one, they keep to themselves and do not mix with other communities. Their community practices Islam and follows their own cultural norms which are quite different from other communities. They have a culture of helping their own and don't have to be related to help each other. The mere fact that one is Somali is enough to receive help from another Somali who is in position to help. Despite their society being a closed one, the Somali community has continued to thrive because their support systems are very strong.

"... the social-cultural-religious ties they have within the community here are really good. You find that they are very attached to each other and they are a very closed society that depend on each other even in terms of businesses and protection"(KII,OPM)

\section{Discussion}


The themes emanating from the results are discussed in this section in relation to what other scholars have found as well as Doyal and Gough's theory of human needs.

While assessing the living conditions of Somali refugees in Nakivale settlement, two broad themes namely; basic needs and security emerged. Our results show that the need to fulfil basic needs and ensure personal security contributes to Somali refugees moving from Nakivale refugee settlement to Kisenyi, Kampala. These findings agree with those of the Doyal and Gough's theory of human needs in that both agree that human needs and wants will trigger movement to that which the place which the human mind believes is better than the status quo (29).

It is therefore imperative that in planning for refugees, movements which have a bearing on issues of social policy and the future welfare of refugee settlements are given a lot more consideration by all actors dealing with refugees. If attention is not paid to such issues, inadequate provision of basic needs to migrant refugee populations will continue and so will the movement.

Further convergence between study results and the theory was in reasons mentioned in search of physical security which is a longing to be autonomous. According to the Doyal and Gough's theory, physical security ensures survivability-a thing most longed for by refugees. Different scholars elsewhere have documented similar findings among refugee populations $(30,31)$.

The theory diverges from the study findings at different points such as: having a non-hazardous work environment and non-hazardous physical environment. There is not much of a work environment to talk about in the settlements apart from small pieces of land given to refugees for subsistence agriculture. Like it has been noted in the results, there is little or no work in the refugee settlements which greatly contributes to the movement of refugees from settlements to urban dwellings. In Europe, similar challenges have been found among refugee populations (32).

While interrogating opportunities that Somali refugees exploit once they reach Kisenyi, Kampala, three broad themes namely: economic benefits, livelihood support and an enabling policy emerged. These themes are in agreement with the Doyal and Gough's theory of needs which concurs that in part, movement of refugees from settlements to urban dwellings is orchestrated by a need for economic security (29). Economic security guarantees autonomy and self-liberation which have been pointed out by several scholars in different contexts $(33,34)$. As refugees find work, basic and more intermediate needs are met resulting into less strife and dependency ultimately resulting into better lives as stipulated by the UN sustainable development goals (35). On the contrary, the theory departs from the study results at the point of livelihood support and enabling policy which may be additions to the existing theory on movement of refugees from settlements to urban dwellings.

None the less, other scholars in West Africa and Europe have also found that movement of refugees from settlements to towns has been fuelled by a need to have better livelihoods $(36,37)$. In addition, evidence shows that refugees often migrate to countries with an enabling environment for work and freedom of 
movement $(38,39)$. While the refugees in our study did not move from one country to another, the observed movement was from a disadvantaged place to a seemingly better one in their perspective.

In understanding the role of Somali support networks in assisting refugees in Kisenyi, Kampala, one theme- nature of the Somali community emerged. Again, the Doyal and Gough's theory of needs highlights the significance of primary relationships as a corner stone for well-knit societies such as the Somali community (29). In our study, we understood that religion and culture are part of what make Somali communities unique. Similarly, in Malaysia, Muslim refugees have been offered a safe haven mainly on the basis of their Islamic faith, a major point of agreement (40).

The major strength of our study is that it builds on evidence by other scholars in as far as understanding what influences movement of refugees from one place to another. This is further strengthened by the use of the Doyal and Gough's theory of human needs in discussing results that would otherwise be abstract.

A major limitation of this study is that only three focus group discussions where held and majority were with females. This may have impacted on the study results since not many views from male Somali refugee were captured. The investigators of the study are aware that the Somali community is predominantly patriarchal and as such, more interviews would have enriched understanding on what really influences the movement especially of the Somali males from the settlement to the urban areas. None the less, the investigators probed the three focus groups to a depth that ensured saturation. Findings from this study may be used to provide greater insights for actors involved in making sure refugees live a more fulfilled life. United Nations agencies can use this information for better planning of resources especially after a significant number of refugees have left the settlement while the central government can use this information to avert a crisis that may arise from pressure exerted on social services by refugees entering the city from the settlement.

\section{Conclusions}

Our findings show that Somali movement from Nakivale refugee settlement to Kisenyi, Kampala is influenced by a need for better basic needs and security; economic benefits, livelihood support and an enabling refugee policy which guarantees freedom of movement. Relatedly, Somali refugee movement is aided by the robust communication network in Kisenyi that relies on the Islamic religion and country background.

\section{Declarations}

\section{ACKNOWLEDGEMENTS}

We are grateful to all the data collectors, refugees who accepted to participate in this study and the different agencies dealing with refugees that supported the data collection process by accepting to be interviewed. 
FUNDING

Special thanks go to Game Trails (U) Ltd for funding this study

AUTHOR CONTRIBUTIONS

PMB and TK conceptualised the study. PMB conducted data collection. PMB, and AB analysed and drafted all versions of the manuscript. All authors read and approved all versions of this manuscript.

\section{CONFLICT OF INTEREST}

The authors declare that they have no conflict of interest.

\section{DATA AVAILABILITY STATEMENT}

The data supporting this study is available on request from the corresponding author. The data are not publicly available due to privacy and ethical restrictions.

Ethics approval and consent to participate

Ethical approval to conduct this study was obtained from the Uganda Martyrs' University ethical review board while all participants provided written informed consent for themselves.

\section{References}

1. IOM. WORLD MIGRATION REPORT 2020. Geneva Switzerland: International Organization for Migration, 2020.

2. Balsari S, Dresser C, Leaning J. Climate Change, Migration, and Civil Strife. Current Environmental Health Reports. 2020;7(4):404-14.

3. Bjørkhaug I. Revisiting the Refugee-Host Relationship in Nakivale Refugee Settlement: A Dialogue with the Oxford Refugee Studies Centre. Journal on Migration Human Security. 2020;8(3):266-81.

4. Ramji-Nogales J, Goldner Lang I. Freedom of movement, migration, and borders. Journal of Human Rights. 2020;19(5):593-602.

5. Finch T. Love and management: Reflections on the 2015 refugee crisis. Juncture. 2015;22(3):230-4.

6. MSF. Iraq. Poor living conditions in Domeez camp put health of Syrian refugees at risk. Medecins Sans Frontiers: Doctors without Borders, 2013.

7. Doyal L, Gough I. Intermediate Needs. A Theory of Human Need. London: Macmillan Education UK; 1991. pp. 191-221.

8. Saunders J, Smith T. Malnutrition: causes and consequences. Clin Med (Lond). 2010;10(6):624-7.

9. Sok P, Gardner S, Bekele T, Globerman J, Seeman MV, Greene S, et al. Unmet basic needs negatively affect health-related quality of life in people aging with HIV: results from the Positive Spaces, Healthy Places study. BMC Public Health. 2018;18(1):644. 
10. UNHCR. Uganda - Refugee Statistics May 2020 Uganda: UNHCR; 2020. Available from: https://data2.unhcr.org/en/documents/details/76877.Convention Relating to the Status of Refugees, (1951).

11. Tong A, Sainsbury P, Craig J. Consolidated criteria for reporting qualitative research (COREQ): a 32item checklist for interviews and focus groups. Int J Qual Health Care. 2007;19(6):349-57.

12. Sandelowski M. Whatever happened to qualitative description? Research in nursing \& health. 2000;23(4):334 - 40.

13. Sandelowski M. What's in a name? Qualitative description revisited. Res Nurs Health. 2010;33(1):7784.

14. Palinkas LA, Horwitz SM, Green CA, Wisdom JP, Duan N, Hoagwood K. Purposeful Sampling for Qualitative Data Collection and Analysis in Mixed Method Implementation Research. Adm Policy Ment Health. 2015;42(5):533-44.

15. Lavrakas P. Encyclopedia of Survey Research Methods. 2008.

16. Thompson DK. Ethnicity and nationality among Ethiopians in Canada's census data: a consideration of overlapping and divergent identities. Comparative Migration Studies. 2018;6(1):6.

17. Hilton $\mathrm{CE}$. The importance of pretesting questionnaires: a field research example of cognitive pretesting the Exercise referral Quality of Life Scale (ER-QLS). Int J Soc Res Methodol. 2017;20(1):21-34.

18. Saunders B, Sim J, Kingstone T, Baker S, Waterfield J, Bartlam B, et al. Saturation in qualitative research: exploring its conceptualization and operationalization. Qual Quant. 2018;52(4):1893-907.

19. Colorafi KJ, Evans B. Qualitative Descriptive Methods in Health Science Research. Herd. 2016;9(4):16-25.

20. Hudson LA, Ozanne JL. Alternative Ways of Seeking Knowledge in Consumer Research. J Consum Res. 1988;14(4):508-21.

21. Putnam LL, Banghart S. Interpretive Approaches. The International Encyclopedia of Organizational Communication2017. p. 1-17.

22. Graneheim UH, Lundman B. Qualitative content analysis in nursing research: concepts, procedures and measures to achieve trustworthiness. Nurse education today. 2004;24(2):105-12.

23. Kitto SC, Chesters J, Grbich C. Quality in qualitative research. The Medical journal of Australia. 2008;188(4):243-6.

24. Morse JM. Critical Analysis of Strategies for Determining Rigor in Qualitative Inquiry. Qual Health Res. 2015;25(9):1212-22.

25. Forero R, Nahidi S, De Costa J, Mohsin M, Fitzgerald G, Gibson N, et al. Application of four-dimension criteria to assess rigour of qualitative research in emergency medicine. BMC Health Services Research. 2018;18(1):120.

26. Casell C, Symon G. Essential Guide to Qualitative Methods in Organizational Research. 2004 2021/05/29. London: SAGE Publications Ltd. Available from: 
https://sk.sagepub.com/books/essential-guide-to-qualitative-methods-in-organizational-research.

27. Reeves $S$, Albert M, Kuper A, Hodges BD. Why use theories in qualitative research? BMJ. 2008;337:a949.

28. Doyal L, Gough I. A theory of human needs. Crit Soc Policy. 1984;4(10):6-38.

29. Beogo I, Darboe A, Oluwafunmilade Adesanya A, Mendez Rojas B. Critical assessment of refugees' needs in post-emergency context: the case of Malian war refugees settled in Northern Burkina Faso. BMC International Health Human Rights. 2018;18(1):38.

30. Odutayo A. Human security and the international refugee crisis. Journal of Global Ethics. 2016;12(3):365-79.

31. Schenner JK, Neergaard A. Asylum-seekers and refugees within Europe and labour market integration. Transfer: European Review of Labour Research. 2019;25(1):13-24.

32. Castelli F. Drivers of migration: why do people move? Journal of Travel Medicine. 2018;25(1).

33. Gheasi M, Nijkamp P. A Brief Overview of International Migration Motives and Impacts, with Specific Reference to FDI. Economies. 2017;5(3):31.

34. Smith MJ. Sustainable Development Goals: genuine global change requires genuine measures of efficacy. Journal of Maps. 2020;16(2):(i)-(iii)..

35. Crawley H, Skleparis D. Refugees, migrants, neither, both: categorical fetishism and the politics of bounding in Europe's 'migration crisis'. Journal of Ethnic Migration Studies. 2018;44(1):48-64.

36. Omata N. Who takes advantage of mobility? Exploring the nexus between refugees' movement, livelihoods and socioeconomic status in West Africa. African Geographical Review. 2018;37(2):98108.

37. Buscher D. Refuge in the City. Social Sciences. 2018;7(12):263.

38. Triggs GD, Wall PCJ. 'The Makings of a Success': The Global Compact on Refugees and the Inaugural Global Refugee Forum. International Journal of Refugee Law. 2020;32(2):283-339.

39. Hoffstaedter G. Refugees. Islam, and the State: The Role of Religion in Providing Sanctuary in Malaysia. Journal of Immigrant Refugee Studies. 2017;15(3):287-304. 